production logistics, mobile robots, intralogistics automation, $3 D$ simulation, IoT sensors

\author{
Kashif MAHMOOD ${ }^{1 *}$ \\ Kristo KARJUST ${ }^{1}$ \\ Tonis RAAMETS ${ }^{1}$
}

\title{
PRODUCTION INTRALOGISTICS AUTOMATION BASED ON 3D SIMULATION ANALYSIS
}

\begin{abstract}
Recent trends in manufacturing such as Industry 4.0 and Smart Manufacturing have brought the researchers' attention to the smart intralogistics in production facilities. Automated guided vehicles (AGV), especially mobile robots play a vital role in this development. On the other hand, industrial internet technologies offered new possibilities for the information exchange between devices, data integration platforms and communication interfaces to advance and facilitate the intralogistics for effective material handling and transportation. In order to analyse the feasibility and effectiveness of the mobile robots in the production area, 3D visualization should be combined with simulation, which provides a comprehensive possibility to evaluate and review the potential solution performance and its consistency before implementing practically into the production floor area. This paper describes a conceptual model based on 3D visualization and simulation and experimental study which help to make the decision according to the input data from the factory environment of the movement of mobile robots in production logistics. Moreover, the Key Performance Indicators (KPIs) are defined to analyse the use-case's process improvement in terms of the time reduction, which leads to increase productivity and cut-down the workers' fatigue.
\end{abstract}

\section{INTRODUCTION}

Smart manufacturing demands the use of the technology and methods like: implementation of the Internet of Things (IoT) in factories and plants; integration of new technologies related to digital twin, augmented reality, and smart sensors for existing production environments. Those methods and technologies support the company management level for effective decision-making. The term that incorporates all those mentioned methods is known as "Industry 4.0", a new word coined at the "Hannover Messe" held in 2011 [1]. The nine pillars of Industry 4.0 are: Big Data and Analytics, Autonomous Robots, Simulation, Horizontal and Vertical System Integration, IoT, Cloud Computing, Additive Manufacturing, Augmented/Virtual Reality (AR/VR), and Cyber Security [2].

\footnotetext{
${ }^{1}$ Mechanical and Industrial Engineering, Tallinn University of Technology, Estonia

*E-mail: kashif.mahmood@taltech.ee https://doi.org/10.36897/jme/137081
} 
The technological roots for the Industry 4.0 are established by data networked production facilities, material handling as well as transporting equipment, which are harnessed with sensors and decentralized Information Technology (IT) intelligence. These intelligent systems for manufacturing intralogistics, which are connected via the Internet, are able to autonomously organize, control, and adapt the sequence of value-added processes and the correspondent logistical functions to exterior requirements. The recent "technology push" in the design and introduction of the autonomous production systems, advancement in digitalization, and automation leads to the expansion of new forms of services and work organization [3]. This new forms of services with collaborative machines, human, and transporting equipment such as Automated Guided Vehicles (AGVs) can be simulated to an extent, but they can be comprehensively understood with a level of trust for the adoption into the industry when the same scale experimental studies and demonstrators are established [4]. The combined effects of 3D simulation with the same level of real demonstrator help to make the efficient decisions and improvements of the target processes.

The high level of automation has been reached in production and intralogistics, but there is still use of human labour for the transportation of goods utilizing handcarts and forklifts, which leads to the higher labour cost and products quality risks. There are other approaches like the installation of conveyors to automate material handling and movement, but they are either fixed, overhead, or floor-based. Therefore, Autonomous Mobile Robots (AMR) are considered to be a potential solution for flexibility and to improve internal logistics efficiency. $3 \mathrm{D}$ visualization and simulation is an essential tool for the validation of the change in the real environment and facilitates to compare the different scansions virtually before the implementation [5,6]. Besides that new industrial internet of things such as smart sensors, communication, and connectivity platforms add more value to the effective and efficient implementation of the change [7]. It helps to control and monitor the change i.e., deployment of AMRs in the real factory environment.

In this paper, authors contributed by developing a conceptual model to analyse the automation of intralogistics for manufacturing, which is based on autonomous mobile robots, 3D visualization and simulation, and IoT sensors for communication. A case study of a food production company was used to demonstrate the relevance and feasibility of the proposed concept.

The proposed concept allows SMEs to integrate the smart technologies of simulation, mobile robots, and IoT sensors to their current intralogistics system, which enables to improve the on-time delivery and reduce the labour costs and fatigues.

\section{LITERATURE REVIEW}

The literature review introduces the state of the art, which is related to the field of this study. It consists of the importance of 3D simulation and visualization, followed by the involvement of autonomous mobile robots for intralogistics, the brief explanation of IoT sensors, and vision technology. Moreover, similar studies and relevant approaches are also referred to in this section. 


\subsection{D SIMULATION AND VISUALIZATION}

The purpose of the simulation is to grasp the insight behaviour of a system. Simulation is beneficial and appropriate to perform experiments and testing different solutions without any expense of physically change of a system, which allows to create an effective production line easier and quicker to accomplish. The ability to animate the system behaviour with time is one of simulation's great advantages. Animation is useful for demonstrations, validation, and debugging [8].

The extensive and often schematic 2D simulation \& visualizations are not able to fulfil such objectives. One possibility is to use Industrial Virtual Reality (IVR) based 3D visualizations, which can be fitted to existing 3D assembly layouts, 3D product models, and process flows generated from simulation models [5]. During this work the purpose is to visualize the simulations at a particular area of the production floor in combination with a realistic representation of the area, besides, the step of assembly or filling of products including the components and tools are used, and the changes in the location of transportation equipment also addressed. This kind of visualization allows a good evaluation of the simulated sequences, which drives beyond established standard 2D simulation and visualizations [9]. $3 \mathrm{D}$ simulation and visualizations of intralogistics operations can be created by integrating the existing production process data and with the 2D layout of the production facilities.

\subsection{AUTONOMOUS MOBILE ROBOT FOR INTRALOGISTICS}

Material Handling Equipment (MHE) is a critical part of material flow for production factory logistics. For more flexibility in the production facilities, new transportation, and material handling methods need to be introduced [10]. MHE such as conveyors, used for automatic material transfer, and a large amount of parts can be moved, they offered temporary buffers, and material transportation between workstations, and they can be provided adequate solution together with forklift and pallet truck [11]. However, these equipment and systems allow a low degree of flexibility in routing compared to the AGVs and autonomous mobile robots. Moreover, autonomous mobile robots show a high level of versatility, as they can be used in various applications and can be reprogrammed depending on the input data changes. There are several developments and implementation of Industrial Robots (IR) into production facilities for the material handling and the different processes applications. Such as IR for the measurement process, the integration of IR in a manufacturing cell for pick and place, also in welding process $[12,13]$. Conversely, there is still a need to do research and study regarding the usage and implementation of mobile robots for material handling in the production field, and how mobile robots can be combined with the industrial internet of things for effective decision-making and improvement of a transportation process.

As the new industrial internet of technologies, smart sensors, and development in artificial intelligence enabled positioning and autonomous navigation for mobile robots, which makes these vehicles to drive in a predefined area not as rigid to move in a defined guided path, that allows larger flexibility. Autonomous mobile robots operate on a decentra- 
lized decision basis, which leads to dynamic routing and scheduling. They are supposed to be small and more agile than traditional AGVs [14]. Furthermore, autonomous mobile robots can fit and access more areas and can be integrated to a higher degree in production workspace, leads to manufacturing flexibility and capable to fulfil the production demands. They are particularly suited for intralogistics operations like transportation and part feeding inside the production facility [10].

\subsection{IoT SENSORS AND VISION TECHNOLOGY}

Due to the recent development in modern manufacturing, most of the production and material handling systems are comprised of embedded technologies like smart sensors, organized through cloud-based solutions. It permits a large amount of data generation and collection that can be used to estimate different KPIs and enables proactive decision making. The ultimate aim of IoT applications in manufacturing is to comprehend smart factories, where machines and material handling resources communicate and are connected in a network. For that purpose, production lines, transportation resources, and existing IT tools of an enterprise should be connected to the internet directly or through external adapters [15].

Autonomous navigation can be achieved by integrating the applications of sensors, cameras, and computer vision into a vehicle. By using the camera and the object detection algorithm, certain 3D details on the motion path can be calculated and transmitted to the robot controller. This information notifies the robot controller about the desired location to be reached and facilitates navigation [16]. Likewise, autonomous navigation can be planned based, where a global map is used and relies on accurate global self-localization which is able to follow a path stated in global coordinates. In a planned based method, a path is defined at first on an available global map that is followed by the mobile robot. Different sensors and cameras can be used for localization in a map-based navigation approach.

\subsection{LIMITATIONS IN EXISTING LITERATURE}

This paper proposes a concept to analyse the automation of production logistics in a timely and coherent way, which is based on 3D simulation, autonomous mobile robots, smart sensors, and KPIs evaluation. There are studies and approaches covered the topic of automation of intralogistics and the use of mobile robots for transportation in production factories [10, 17, 18]. For production companies, such approaches and tactics are difficult to construct and adopt. Moreover, there are studies about the increased flexibility in intralogistics by suitable learning scenarios to grasp the energy-related dependencies of various transport technologies [19] and implementation of an autonomous industrial mobile robot in industrial applications that considered mobile robot technology, planning and scheduling, and communication [20]. However, they are lacking in the exploration of simulation and visualization tools, also recent studies are hardly providing a synchronized way to investigate the automation of intralogistics. This work provides a harmonized 
conceptual model to evaluate the automation of production logistics via simulation and mobile robots. For more flexibility in the production facilities, new transportation, and material handling methods need to be introduced [10]. Mostly used MHE such as conveyors used for automatic material transfer, forklift and pallet truck as mechanized material transportation equipment. However, these equipment allow a low degree of flexibility in routing compared to the AGVs and autonomous mobile robots. Moreover, mobile robots show a high level of versatility, for they can be used in various applications and can be reprogrammed as desired.

\section{CONCEPTUAL MODEL AND CASE STUDY}

The development of the conceptual model to analyse and implement the change i.e., automation of intralogistics for manufacturing was established. The case study practice was used as a research method. The general conceptual model is brought out in Fig. 1.

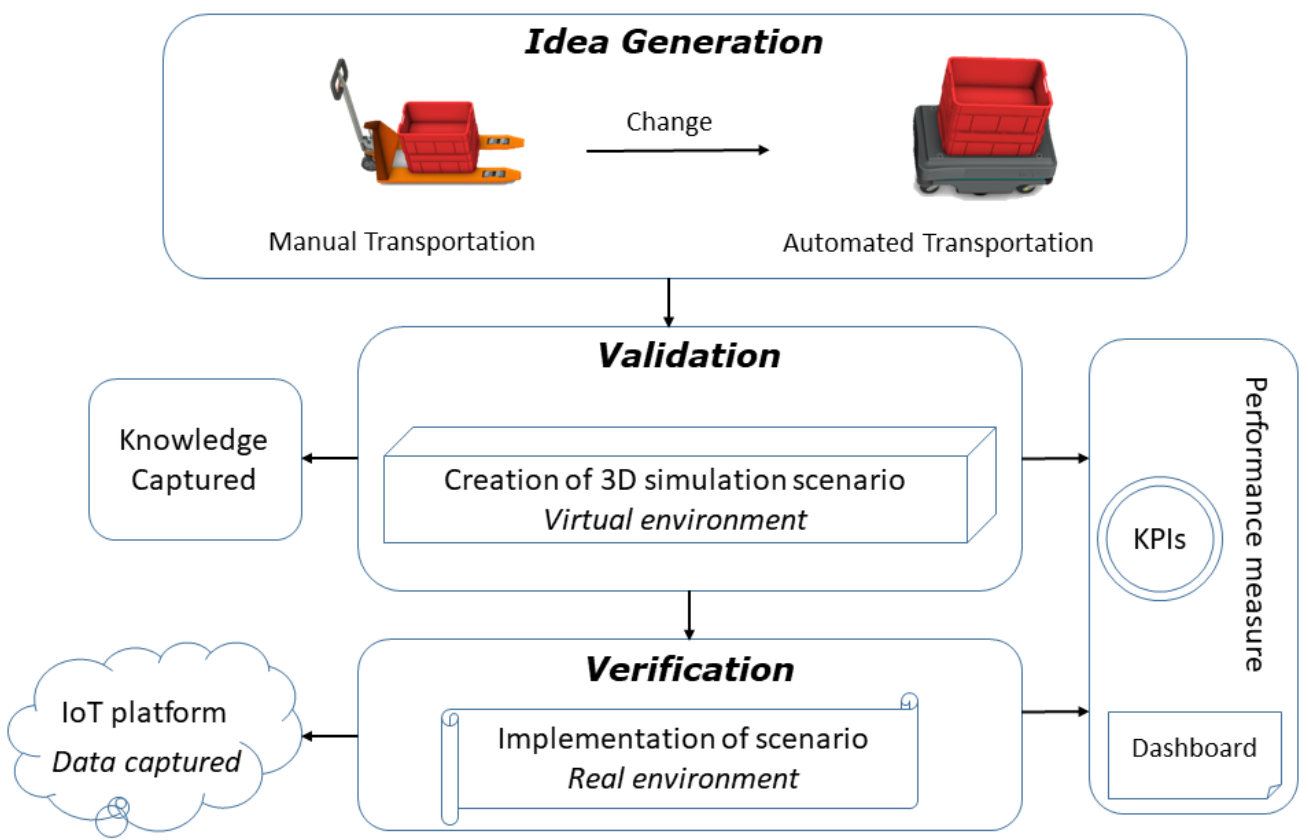

Fig. 1. General conceptual model to analyse the automation of production logistics

The model consist of three main steps, first is the idea generation, which is about the particular activity that should be automated and the purpose of the automation. The second step validates the change or implementation of mobile robots for transportation in a virtual environment, also facilities to compare the scenarios based on target KPIs and the knowledge should be used for the deployment of mobile robots in the real environment (third step). In the third step, data (movement of robots) should be captured from the real scene via a smart sensor and navigation plan, where the IoT platform used for the connectivity of different 
resources and storing data, which is later used for the estimation of KPIs. The third step not only verifies the virtual environment setup (layout and simulation), but also helps to prove the estimated KPIs from the simulation results.

\subsection{DESCRIPTION OF A CASE STUDY}

The proposed conceptual model was applied to a food manufacturing company intralogistics process, the company produces and sells prepared foods. Although, the company has the combined elements of flexibility and capacity in terms of production volume and product portfolios, which facilitates them to accomplish not only industrial but smaller-scale orders as well. However, most of the production activities are operated manually, especially the production floor logistics. The transportation and material handling of goods (raw material, WIP, and finished products) are one of the key activities on the production floor, and the improvement in this process by means of time reduction helps to increase productivity and cut-down the workers' fatigue. Therefore, the company intends to explore and adopt the automation possibilities in production logistics, and the idea was to implement autonomous mobile robots for the material transportation within the production floor and the company was keen to adopt this change i.e., the collaboration of mobile robots and workers.

The production facility handles the transportation of boxes (containers) by humanworker using hand lifters and special wheels. Approximately 4000-5000 red boxes are moving daily in production. In the case of logistics, the waybills (bill of materials) are used and the order is executed through oral commands. In this experiment, three basic logistics routes are considered and their respective workflows are:

- WF-1 - The transport-worker periodically reviews the production units and evaluates the number of boxes needed to move somewhere. Empty boxes are transported from the washing department to a special wheel-base;

- WF-2 - The production worker takes boxes for the production unit and brings them to the production line. When the products are ready, they put the goods in the boxes and transport them to the warehouse;

- WF-3 - The warehouse worker puts the raw material into the boxes and carrying them to the transport-base. The warehouse worker carries these wheel-bases to the intermediate storage of raw material.

\subsection{KEY PERFORMANCE INDICATORS FOR ANALYSIS}

Proper KPI selection, estimation and implementation are prerequisites to enhance the performance of the production processes [21, 22]. To keep in mind, the desired goals of automation and criticality of the logistic process, four major KPIs were defined to analyse the performance of the intralogistics process and compare the current situation (a manual process) with the automated production logistic via mobile robots. The KPIs used to measure the performance are: 
$\mathrm{P}_{1}-$ Defects during the transportation

$\mathrm{P}_{2}-$ On-time delivery
$\mathrm{P}_{3}$ - Inventory turnover

$\mathrm{P}_{4}-$ Labour cost for transportation

Defects during the transportation were the irregularities in the number of boxes transported, transported at the wrong place, and incorrect goods transported. Those defects are caused due to the messy corridors, worker's fatigues, and lack of right information.

On-time delivery is the delivery of empty red boxes on-time at designated places in the production area. It helps to ensure the availability of empty boxes in a sufficient amount so that there is a reduction in waiting time for empty boxes and subsequently increment in ontime delivery.

Inventory turnover - one of the goals was to fill empty red boxes with finished goods (from production lines). It means to turn empty boxes into full boxes and can be defined as:

$$
\text { Average Inventory }(I)=\text { Throughput }(R) x \text { Average Flow Time }(T)
$$

\section{Hence, Inventory turnover $=R / I$}

Labour cost for transportation helps to realize the impact of mobile robots in monetary terms. The deployment of mobile robots leads to reduce the labour cost for transportation. Simple costing can be formulated as:

$$
\text { Cost }=\text { Investment }+ \text { Operating cost }(\text { fixed and variable })
$$

Although, there are initial investments to acquired mobile robots. However, after the payback period, there would be an increment in profit margin.

\subsection{CREATION OF 3D SIMULATION SCENARIO}

The simulation model of the case production facility can be seen in Fig. 2, Fig. 3 and Fig. 4 which were created on the Visual Components (VC) 4.2 [23]. The main focus is to setup the production layout and simulates internal logistics. The target is to analyse the transportation of boxes (red colour boxes) that are used to carrying raw material from the warehouse to the production area, finished goods from the production area to the warehouse, and empty boxes from the washing area to production. The workplaces with different colours (red, yellow, and green) in Fig. 2 corresponds as follows:

- Red workplaces are the buffer for empty boxes

- Yellow workplaces are the buffer for Raw Material (RM)

- Green workplaces are the buffer for Finish Goods (FG)

The purpose of Fig. 2 is to define the designated working areas that were used in the factory floor for analysis and it helps to measure the distances between the working areas as well. Later those distances were capitalized to adjust the speed of mobile robots and use as an input parameter during the simulation. Figure 3 defines the routing map of mobile robots on a full scale and helps to plan the movement of mobile robots in the simulation environment. 
The 2D factory floor map with the exact physical dimensions was imported into the virtual world and 3D environment of 1x1 scale was ramp-up on it, it represents the digital replica of the physical factory. The floor lines are clearly visible and the movement of AMRs can be observed i.e., the transportation of boxes by AMRs from the designated buffer areas to the production area on the factory floor and vice versa. It assists to find out the distance covered, time consumed and boxes transferred by AMRs during the simulation that aids to formulate the defined KPIs and later used for the comparison of manual transportation versus automated transportation by AMRs as criterions. Furthermore, Fig. 4 shows the 3D simulation of the factory floor for the holistic visualization and evaluation of the transportation of boxes via mobile robots.

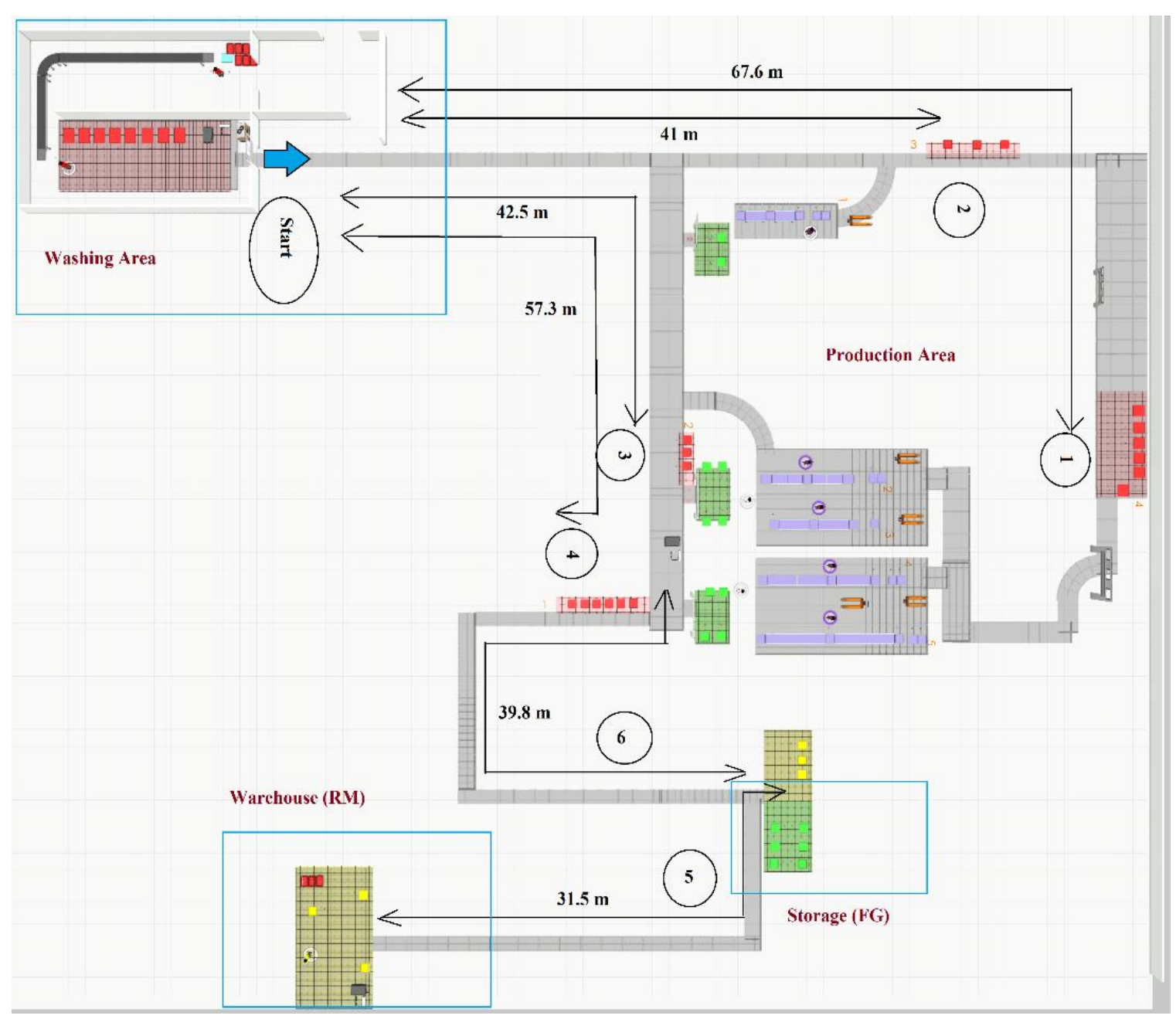

Fig. 2. Simulation scenario of production facility with the marking of working areas

AMRs were deployed to transport the boxes from one place to another in the virtual environment. There is the movement of 4000 boxes approximately in the production facility for the processing of different products in 12 hours. The major concern is the availability of empty boxes at red workplaces (buffer) at the right time, as those empty boxes are being used to store the ready products and then transport to the warehouse. 


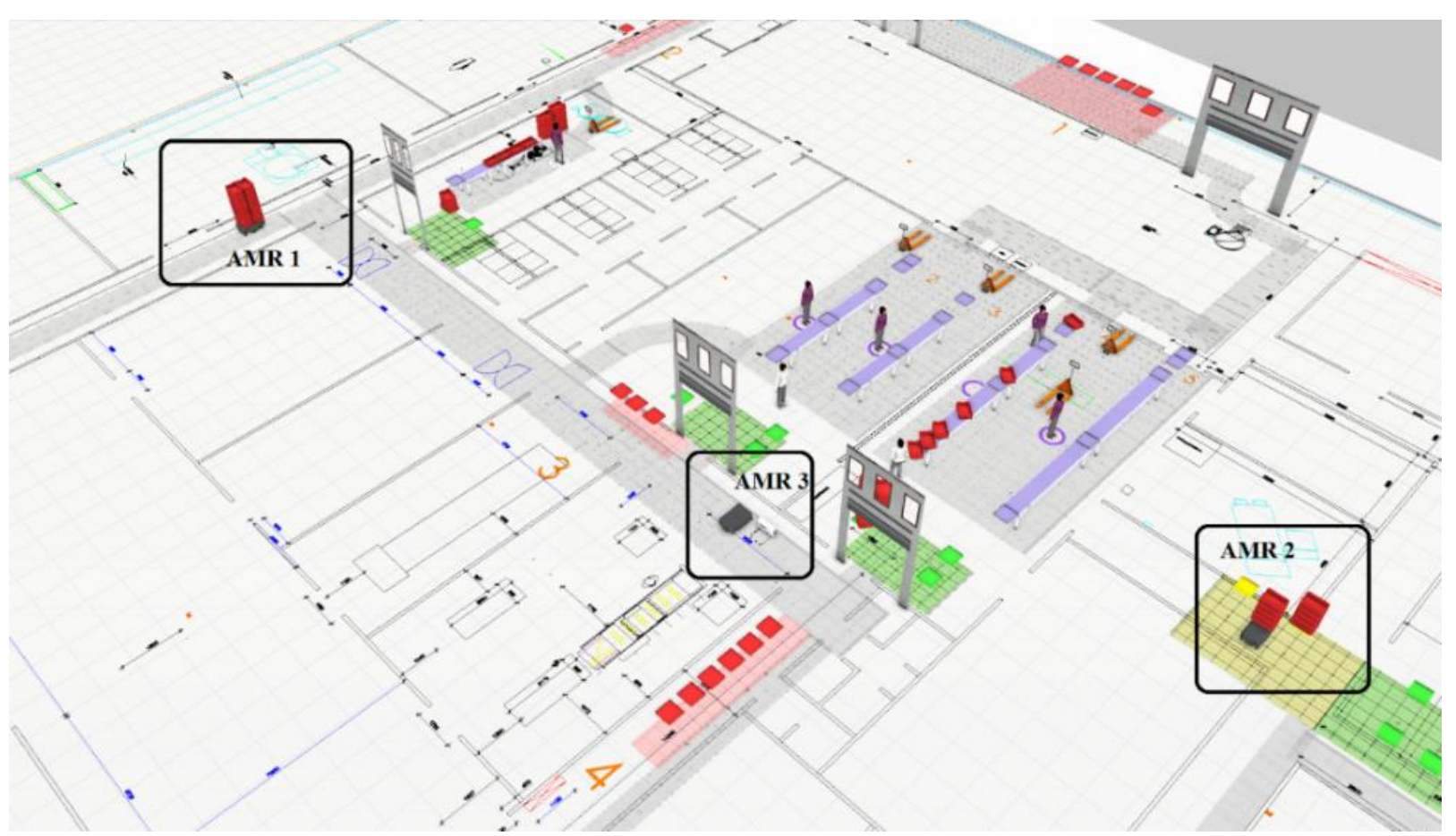

Fig. 3. Simulation scenario of production facility with the marking of mobile robots' routes

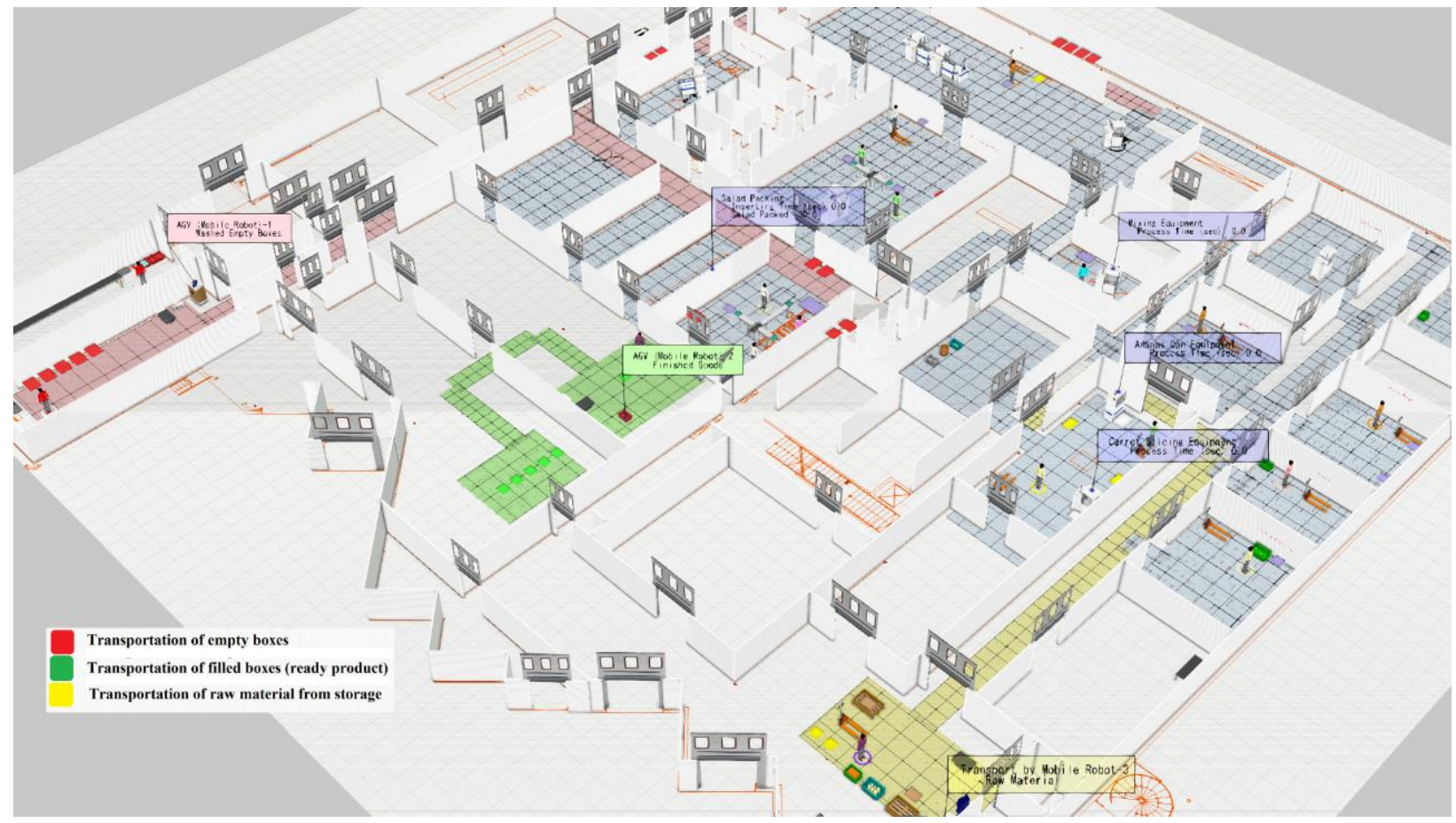

Fig. 4. 3D simulation model of production facility (virtual environment: a holistic view)

There are three AMRs, each is designated to different areas such as transport empty boxes from the washing area, raw material from the warehouse, and finish goods from production respectively. The process steps are as follows: 
- AMR-1 - transports empty boxes from the washing area to different designated locations (red buffer) in production. AMR-1 carried 20 empty boxes in each run.

- AMR-2 - transports a box of raw material in each run to a particular location (yellow buffer) in the production area.

- Production workers pick the empty boxes from the designated locations, bring to the production lines, and filled boxes with products.

- AMR-3 - picks the filled boxes from the production area and transport them to the finish goods area (green buffer).

\subsection{IMPLEMENTATION OF SCENARIO IN REAL ENVIRONMENT}

The 3D simulation model (virtual environment) was implemented in the production facility (real environment) to verify the deployment of mobile robots for the production logistics process. The communication model of various devices such as mobile robots and sensors that were installed for the experimental study is shown in Fig. 5. The Hybrid Production System (HPS) was designed to enable interoperability and collaboration between different sub-systems. The HPS enables the integration with hardware devices and software of the end-users such as, for example, on the one hand the mobile robots and sensors in the warehouse, and on the other hand, the enterprise applications such as ERPs, MES and so on. The IoT Nodes layer (agent nodes) are the components of the communication model that interact with the physical world. For instance, they can interact by sensing, e.g., sensor agent node, by acting, e.g., robotic agent nodes. The modules of which these nodes are made of, can interact with the layer of Software System by exchanging messages with the layer of Cyber Physical Middleware and they either directly operate on these messages or translate them to an appropriate format for internal use through their communication sub-modules. Moreover, IoT nodes layer can talk to each other and with the other components of the communication model, as well as with Enterprise Applications, by means of the Cyber Physical Middleware layer. Similarly, the software applications layer interact with IoT nodes layer in addition to Enterprise Applications by means of message exchange via Cyber Physical Middleware.

The Human Machine Interface (HMI) module provides the task monitoring and control, which enables continuous monitoring and visualization of information connected to other modules such as the sensor module [24, 25]. HMI can collect data from enterprise applications. Furthermore, it can be used for the task specification to formulate a task based on the task parameter. The sensing and perception module provides information suitable for safe and accurate motion planning to the Robot Agent Node. It also helps the mapping the structure of the manufacturing shop floor for the components involved in navigation.

For the case study, the cyber physical middleware was connected to the simulation for the optimization purpose, which is also linked to the Enterprise Resource Planning (ERP) system through data management node. The production planning and scheduling data from ERP feeds to the simulation to carry out the sensitivity analysis and then to figure out the best optimize solution for the whole production process.

The input parameters such as location, transportation time and loading \& unloading of mobile robots were captured through sensors. The Sensor Agent Node (SAN) module was 
linked to the Raspberry Pi 3 device, which was connected to the infrared sensors. A 3D printed packet was made to house the Raspberry Pi and the sensor. SAN modules were added to the routes of the mobile robots, precisely at the loading and unloading area for robots. When robots passed through, they detect the robot and crates (red boxes), send signals, and time stamp was recorded that can be observed on Human Machine Interface (HMI).

For mobile robots testing, first, the mapping was done on the designated routes by moving them around the routes with joysticks and then moving it to a starting point. After they could move anywhere that has been scanned. In the later stage, LiDAR sensors were installed on the robots that help to scan the surrounding and allows to create a map for the mapping purpose. Moreover, it facilitates to identify objects in their path like humans so they can stop. Robot Agent Node (RAN) was linked to robots so while moving around a robot sends its location data in real-time to the IoT platform, which is then displayed to the user via HMI.

Six routes were tested in the production facility, tested routes can be depicted in Fig. 6 . Data about timings and the number of boxes transferred were observed that used later for the KPIs estimation.

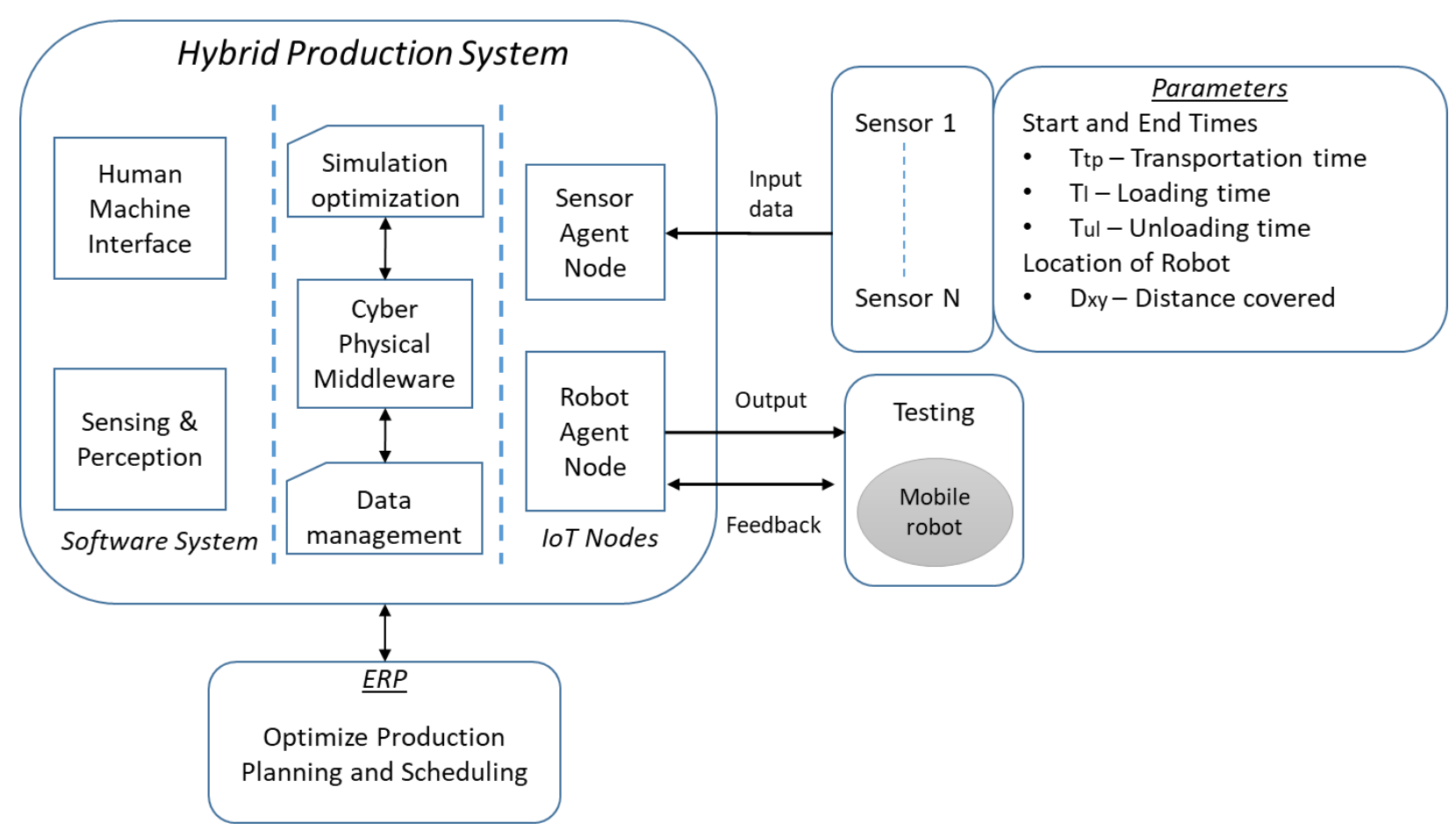

Fig. 5. Communication of entities in the factory environment (implementation of scenario)

Results of virtual and real scenarios for the automation of the intralogistics process via mobile robots were compared and presented in table 1 . The observations were evaluated based on the target KPIs and positive changes were noted. The KPI-s implemented can be utilized for further optimization of the intralogistics process based on working group long time experience in engineering optimization [26]. 


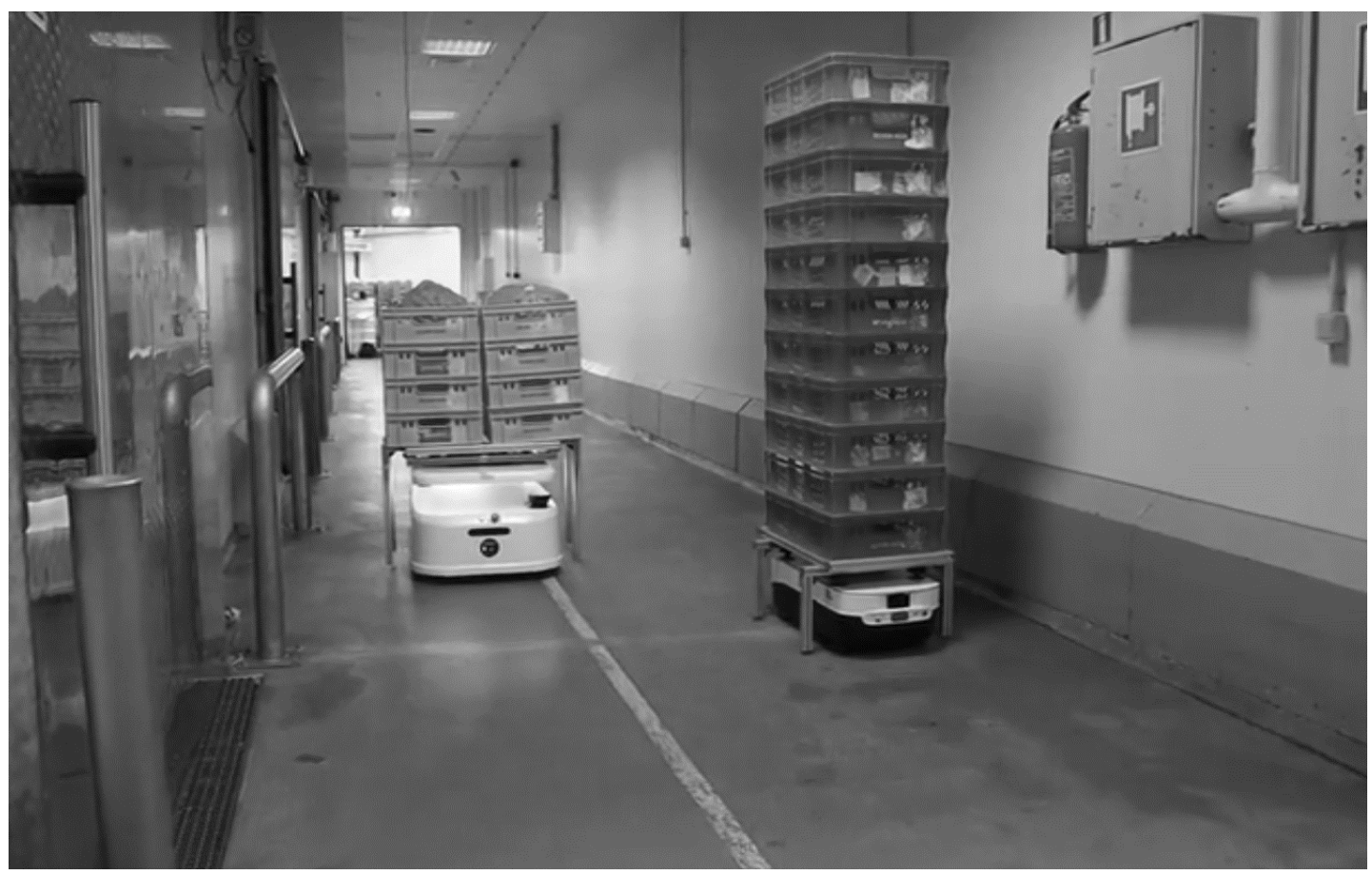

Fig. 6. Experimental study in the factory environment

Table 1. Results based on the defined KPIs

\begin{tabular}{|c|c|c|c|c|}
\hline KPI & Current Scenario (manual) & $\begin{array}{l}\text { Virtual Scenario } \\
\text { (automated) }\end{array}$ & Real Scenario (automated) & $\begin{array}{l}\text { Estimated } \\
\text { improvement }\end{array}$ \\
\hline $\begin{array}{l}\text { Pl: } \\
\text { Defects }\end{array}$ & $\begin{array}{l}\text { Irregularities existed due to the } \\
\text { messy corridors (routes) with } \\
\text { random boxes (crates) }\end{array}$ & $\begin{array}{l}\text { Irregularities did not exist as } \\
\text { in the simulation the } \\
\text { designated routes were } \\
\text { clearly defined for robots }\end{array}$ & $\begin{array}{l}\text { Irregularities were mitigated } \\
\text { as the implementation of } \\
\text { robots in a real environment } \\
\text { leads to neat and clean routes. }\end{array}$ & $\begin{array}{l}10 \% \text { reduction } \\
\text { in existing } \\
\text { transportation } \\
\text { defects }\end{array}$ \\
\hline $\begin{array}{l}\text { P2: } \\
\text { On-time } \\
\text { delivery }\end{array}$ & $\begin{array}{l}\text { Insufficient amount of boxes at } \\
\text { the right time and at the right } \\
\text { place. High waiting time at } \\
\text { production lines }\end{array}$ & $\begin{array}{l}\text { Simulation enables to plan } \\
\text { the number of boxes at right } \\
\text { time and place. For } 12 \text { hours } \\
\text { simulation run with } 3 \\
\text { robots, minor waiting time } \\
\text { was overserved. }\end{array}$ & $\begin{array}{l}\text { On-time deliveries of empty } \\
\text { red boxes were improved as } \\
\text { robots connected to the IoT } \\
\text { platform, communication } \\
\text { between them facilitate the } \\
\text { availability of empty boxes at } \\
\text { the right time and at the right } \\
\text { place. }\end{array}$ & $\begin{array}{l}5 \% \text { increase in } \\
\text { on-time } \\
\text { delivery }\end{array}$ \\
\hline $\begin{array}{l}\text { P3: } \\
\text { Inventory } \\
\text { turnover }\end{array}$ & $\begin{array}{l}\text { Inadequate inventory turnover } \\
\text { due to the lack of boxes. The } \\
\text { throughput was } 321 \text { boxes per } \\
\text { hour. }\end{array}$ & $\begin{array}{l}\text { For an hour simulation run } \\
\text { in the virtual setup of the } \\
\text { same scale, throughput was } \\
336 \text { boxes. }\end{array}$ & $\begin{array}{l}\text { Sensors data and controlled } \\
\text { planning of robots enabled to } \\
\text { improve inventory turnover. }\end{array}$ & $\begin{array}{l}5 \% \text { increase in } \\
\text { inventory } \\
\text { turnover }\end{array}$ \\
\hline $\begin{array}{l}\text { P4: } \\
\text { Labour } \\
\text { Cost }\end{array}$ & $\begin{array}{l}\text { Manual transportation incurs } \\
\text { cost, when human labour } \\
\text { realized fatigue due to } \\
\text { repetitive activities. }\end{array}$ & $\begin{array}{l}\text { Enables effective planning } \\
\text { to allocate the workers and } \\
\text { robots for the right and } \\
\text { productive job. }\end{array}$ & $\begin{array}{l}\text { The proper planned } \\
\text { implementation of robots } \\
\text { leads to a reduction in } \\
\text { operating transportation costs. } \\
\text { As the number of logistic } \\
\text { workers decreased. }\end{array}$ & $\begin{array}{l}15 \% \text { reduction } \\
\text { in the labour } \\
\text { cost }\end{array}$ \\
\hline
\end{tabular}




\section{CONCLUSION}

The proposed conceptual model is a contribution to evaluate the automation of the intralogistics process and to implement mobile robots for production logistics. This work presents how to automate a production logistics process in a harmonized way, which starts with idea generation, validation through 3D simulation and visualization, followed verification by an experimental study in the real environment. The test case ensured the effective use of 3D simulation and visualization helped to reduce the installation time of robots. With the defined KPIs analysis and experimental study, it is technically feasible to use mobile robots for intralogistics, and it may enhance the proactive decision making as well. Moreover, the industrial internet of technologies helps to implement and control the autonomous mobile robots efficiently. Applied conceptual model improved the case company indoor logistics by reducing waiting time in production, the increment of on-time delivery, and decreasing the defects during the transportation process. Mobile robots provide more flexibility and a better possibility to make investments in stages according to increases in required production capacity. The proposed model can be replicated in the future to other companies that are dealing with similar business processes and production.

\section{ACKNOWLEDGEMENTS}

INTERREG project VIR19004 Innovation Framework for Challenge Oriented Intelligent Manufacturing (INforM); H2020 program project VE19030 Autonomous Mobile Robot for intralogistics at Kulinaaria OÜ; the Estonian Centre of Excellence in Zero Energy and Resource Efficient Smart Buildings and Districts, ZEBE, grant TK146 funded by the European Regional Development Fund; and the Estonian Research Core Infrastructures Roadmap project TT2 Smart Industry Centre (SmartIC).

\section{REFERENCES}

[1] GUNAL M.M., 2019, Simulation for Industry 4.0: Past, Present, and Future, Springer.

[2] ERBOZ G., 2017, How to Define Industry 4.0: Main Pillars of Industry 4.0, $7^{\text {th }}$ International Conference on Management, Nitra, Slovakia.

[3] CLAUSEN U., LANGKAU S., KREUZ F., 2019, Advances in Production, Logistics and Traffic, Proceedings of $4^{\text {th }}$ Interdisciplinary Conference on Production Logistics and Traffic, Springer.

[4] VENKATAPATHY A.K., BAYHAN H., ZEIDLER F., HOMPEL M., 2017, Human Machine Synergies in IntraLogistics: Creating a Hybrid Network for Research and Technologies, Proceedings of the Federated Conference on Computer Science and Information Systems, 1065-1068.

[5] MASIK S., SCHULZE T., RAAB M., LEMESSI M., 2016, Comprehensive 3D Visualization of Simulated Processes in Virtual Factories, International Conf. Modeling, Sim. and Vis. Methods, 50-56.

[6] MAHMOOD K., KARAUlOVA T., OTTO T., SHEVTSHENKO E., 2019, Development of Cyber-Physical Production Systems Based on Modelling Technologies, Proceedings of the Estonian Academy of Sciences, 68, 348355.

[7] MÖRTHA O., EMMANOUILIDIS C., HAFNER M., SCHADLER M., 2020, Cyber-Physical Systems for Performance Monitoring in Production Intralogistics, J. of Computers \& Industrial Eng., 142, 1-10.

[8] MAHMOOD K., KARAULOVA T., OTTO T., SHEVTSHENKO E., 2017, Performance Analysis of a Flexible Manufacturing System, Procedia CIRP, 63, 424-429.

[9] PAAVEL M., KARJUST K., MAJAK J., 2017, PLM Maturity Model Development and Implementation in SME, Procedia CIRP, 63, 651- 657. 
[10] FRAGAPANE G., IVANOV D., PERON M., SGARBOSSA F., STRANDHAGEN J.O., 2020, Increasing Flexibility and Productivity in Industry 4.0 Production Networks with Autonomous Mobile Robots and Smart Intralogistics, Annals of Operations Research, Springer.

[11] SULE D.R., 2019, Manufacturing Facilities: Location, Planning, and Design, Boca Raton, CRC Press.

[12] MOSALLAEIPOUR S., NEJAD M.G., SHAVARANI S.M., NAZERIAN R., 2018, Mobile Robot Scheduling for Cycle Time Optimization in Flow-Shop Cells, a Case Study, Production Engineering, 12, 83-94.

[13] KUTS V., TAHEMAA T., OTTO T., SARKANS M., LEND H., 2016, Robot Manipulator Usage for Measurement in Production Areas, Journal of Machine Engineering, 16/1, 57-67.

[14] KANGRU T., RIIVES J., OTTO T., KUTS V., MOOR M., 2020, Optimisation of Decision-Making Process in Industrial Robot Selection, Journal of Machine Engineering, 20/1, 70-81.

[15] MAHMOOD K., LANZ M., TOIVONEN V., OTTO T., 2018, A Performance Evaluation Concept for Production Systems in an SME Network, Procedia CIRP, 72, 603-608.

[16] WURLlA C., FRITZB T., HERMANNB Y., HOLLNAICHERB D., 2018, Production Logistics with Mobile Robots, ISR, $50^{\text {th }}$ International Symposium on Robotics, 213-218.

[17] MICHALOS G., KOUSI N., MAKRIS S., CHRYSSOLOURIS G., 2016, Performance Assessment of Production Systems with Mobile Robots, Procedia CIRP, 41, 195-200.

[18] FISCHER M., RENKEN H., LAROQUE C., SCHAUMANN G., DANGELMAIER W., 2010, Automated 3DMotion Planning for Ramps and Stairs in Intra-Logistics Material Flow Simulations, Proceedings of the 2010 Winter Simulation Conference, 1648-1660.

[19] SCHOLZ M., et al., 2016, Integrating Intralogistics into Resource Efficiency Oriented Learning Factories, Procedia CIRP, 54, 239-244.

[20] NIELSEN I., DANG Q., BOCEWICZ G., BANASZAK Z., 2017, A Methodology for Implementation of Mobile Robot in Adaptive Manufacturing Environments, Journal of Intelligent Manufacturing, 28, 1171-1188.

[21] KAGANSKI S., MAJAK J., KARJUST K., TOOMPALU S., 2017, Implementation of Key Performance Indicators Selection Model as Part of the Enterprise Analysis Model, Procedia CIRP, 63, 283-288.

[22] KAGANSKI S., MAJAK J., KARJUST K., 2018, Fuzzy AHP as a Tool for Prioritization of Key Performance Indicators, Procedia CIRP, 72, 603-608.

[23] VISUAL COMPONENTS PREMIUM 4.2, https://www.visualcomponents.com/, (accessed 15 March 2020).

[24] SNATKIN A., EISKOP T., KARJUST K., MAJAK J., 2015, Production Monitoring System Development and Modification, Proceedings of the Estonian Academy of Sciences, 64, 567-580.

[25] HERRANEN H., KUUSIK A., SAAR T., REIDLA M., LAND R., MÄRTENS O., MAJAK J., 2014, Acceleration Data Acquisition and Processing System for Structural Health Monitoring, Proceedings of the IEEE International Workshop on Metrology for Aerospace, 244-249.

[26] MAJAK J., POHLAK M., 2010, Optimal Material Orientation of Linear and Non-Linear Elastic 3D Anisotropic Materials, Meccanica, 45/5, 671-680. 